\title{
Complaints of Paediatric Patients After Dental Treatment Under General Anaesthesia I: Pain. A Prospective Observational Study.
}

\section{Andrea Radácsi}

Pecsi Tudomanyegyetem Altalanos Orvostudomanyi Kar

\section{Krisztián Katona}

Pecsi Tudomanyegyetem Altalanos Orvostudomanyi Kar

\section{Nelli Farkas}

Pecsi Tudomanyegyetem Altalanos Orvostudomanyi Kar

\section{Tamás Kövesi}

Pecsi Tudomanyegyetem Altalanos Orvostudomanyi Kar

\section{Ildikó Szántó}

Pecsi Tudomanyegyetem Altalanos Orvostudomanyi Kar

\section{Balazs Sandor ( $\nabla$ drsandorbalazs@gmail.com )}

Pecsi Tudomanyegyetem Altalanos Orvostudomanyi Kar

https://orcid.org/0000-0001-6612-9817

\section{Research article}

Keywords: pain management, general anaesthesia, dental treatment, local anaesthesia, NSAID, opioid

Posted Date: August 4th, 2020

DOl: https://doi.org/10.21203/rs.3.rs-45865/v1

License: (9) (i) This work is licensed under a Creative Commons Attribution 4.0 International License. Read Full License 


\section{Abstract}

Background: Dental treatment under general anaesthesia for children is a useful option in behaviour management. However, this treatment modality may also be accompanied by considerable postoperative pain. We aimed to specify factors related to postoperative pain and those that alleviate complaints.

Methods: Children treated in general anaesthesia and their parents voluntarily participated in the study. Pain was reported daily by children using Wong Baker FACES Pain Rating Scale and by caregivers, using a yes/no questionnaire during hospitalization and throughout the postoperative week. The relation of patient and operation linked factors were evaluated in accordance with the duration and severity of pain.

Results: Based on children's responses and parental feedback, no significant difference was found in pain level between extraction and non-extraction cases. Intraoperative local anaesthesia did not influence pain during hospitalization. Compared to other analgesics postoperative intravenous opioid administration was more effective in pain management. Older patients reported more durable and severe pain during the postoperative week. Treatment time, airway management and the class of extracted primary tooth (molar, anterior) significantly influenced pain during postoperative week. Additionally, parental questionnaires revealed correlation between gender and postoperative pain.

Conclusion: Few of the influencing factors are alterable, but with precise and meticulous treatment planning postoperative pain, thereby the distress on families may be reduced.

\section{Background}

Dental interventions under general anaesthesia (DTGA) are routinely performed in cases where outpatient dental treatment cannot be accomplished [1]. The indications of DTGA include anxiety, challenging behaviour, non-cooperative patients, extended and severe dental disease [2,3]. Although there are behaviour management techniques available in paediatric dentistry ("tell-show-do", positive reinforcement, physical restraint, etc.), in some cases they are insufficient for adequate treatment. DTGA is a well-established manner of dental care. Comprehensive treatment positively affects the oral healthrelated quality of life of children and patients with intellectual disabilities [4-6]. Nevertheless, several complications are associated with DTGA, which may be distressing for the patients and their families [7]. We must be aware of both the benefits and disadvantages to minimize the chance of complications and maximize the success of our treatment [8].

Complications related to general anaesthesia (GA) are rare nowadays $[9,10]$. This may be due to the highly trained specialists, safety standards, well-equipped surgeries and modern, commonly used drugs with less side-effects $[11,12]$. However, the United States Food and Drug Administration warns that the prolonged (more than 3 hours) or repeated use of GA in children younger than 3 years may negatively affect the development of children's brains [13]. 
On the other hand, complaints (e.g.: pain, bleeding, nausea, vomiting) are frequent in relation to GA or dental interventions. Among these complaints, pain is one of the most widely reported [14, 15]. Pain management is a pivotal point in paediatric dentistry. Systemic analgesics could be used to reduce pain intra- and postoperatively [16]. Opioids, non-steroidal anti-inflammatory drugs (NSAIDs) and acetaminophen are commonly administered systemic analgesics. Local anaesthesia (LA) during DTGA is frequently used for surgical procedures to decrease postoperative pain. Lidocaine is one of the most widely used pharmacological agents for LA in the dental practice $[17,18]$. The use of LA during DTGA is a rather controversial topic. Numbness caused by LA may increase the occurrence of cheek, lip or tongue biting resulting in painful traumatic ulceration $[16,18,19]$, on the other hand it may reduce postoperative pain [16].

We aimed to determine the factors contributing to postoperative pain after DTGA. In conjunction with these factors, our goal was to specify the circumstances that can reduce the incidence, severity and duration of pain in order to provide applicable propositions. As part of our study, other complaints and complications (bleeding) will be discussed in a subsequent paper.

\section{Materials And Methods}

\section{Patients}

Our study was approved by the local ethics committee of the university (Regional Research Ethics Committee, Clinical Centre, University Pecs, Hungary, No.: 6823). All methods were performed in accordance with the relevant guidelines and regulations. Participants underwent DTGA at our division (Paediatric Dentistry, Department of Dentistry, Oral and Maxillofacial Surgery, Medical School and Clinical Centre, University of Pecs, Hungary) between 2016 and 2018 in the form of day-care surgery. The parents/guardians of patients were thoroughly informed about the anaesthesia and dental treatment plan at the preoperative consultation. The information sheet and consent form about the study were handed out to be reviewed at home. Written informed consent was obtained from the guardian of all individual participants included in the study. Patients were treated by qualified paediatric dentists (consultant in paediatric dentistry), or by resident doctors under the supervision of a paediatric dentists. Indications for DTGA included lack of cooperation, extensive treatment due to multiplex caries lesions, and, less commonly, dental trauma and its inflammatory consequences where other behavioural management was unsatisfactory. None of the patients had any mental disabilities or notable general diseases, they were classified ASA 1 according to the American Society of Anesthesiologists.

\section{Questionnaire to determine the level of experienced pain}

Two questionnaires were handed out to the volunteers. The children received a standard Wong-Baker FACES ® Pain Rating Scale (WBS) questionnaire for the evaluation of pain ranging from 0 to 10 . A second questionnaire, a yes/no answer sheet was administered to the parents/guardians related to the frequently reported complications/complaints of the child after DTGA. To determine the baseline pain (before premedication and surgery), we explained the children the scale and asked them to colour the first 
WBS figure accordingly. After surgery the patients were monitored in the ward for at least 6 hours, before discharge. During this hospitalization period (observation) both the guardians and the children reported their experiences on the corresponding line of their previously specified questionnaire. The data collected from caregivers comprise the presence of oral, nasal pain and sore throat separately, as well as numbness experienced by the patients. The questionnaires were filled in right after awakening, 3 hours and 6 hours after surgery during hospitalization. Both questionnaires (patient's WBS and parental) included 7-day self-administered forms, with the same questions repeated each day during the postoperative week. These were to be completed at home and returned to the office at the follow-up appointment. Patients who failed to return the questionnaires or attend the follow-up appointment were excluded from the study.

\section{Other parameters}

Parameters that may affect the pain level of the patients were collected from the regularly applied medical record, none of these were affected by the study, and no randomization was applied for the treatments or medication. These included: age, gender, length of surgery, airway device (laryngeal mask airway-LMA, nasotracheal intubation-NTI), number and types of interventions (focusing on the amount and tooth extracted), and the type of pre-, intra- and postoperative medications used (Table 1.). LA and antibiotics were administered only in extraction cases, at the operator's discretion. 
Table 1

Medications administered to patients receiving dental treatment under general anaesthesia $\left({ }^{\star}\right.$ Route of administration, LA: local anaesthesia, NSAID: non-steroidal anti-inflammatory drug, p.o.: per os; i.v.: intravenous; sm. infiltr.- submucosal infiltration). Optional administration was left to the operator's discretion.

\begin{tabular}{|c|c|c|c|c|c|}
\hline & $\begin{array}{l}\text { Type of } \\
\text { medication }\end{array}$ & Active agent & Trade name, specification & $\begin{array}{l}\text { Route of } \\
\text { admin.* }\end{array}$ & $\begin{array}{l}\text { Unified/ } \\
\text { Optional }\end{array}$ \\
\hline \multirow{2}{*}{$\begin{array}{l}\text { Pre- } \\
\text { operative }\end{array}$} & Sedative & $\begin{array}{l}\text { midazolam } \\
\text { syrup }\end{array}$ & compounded medication: $1 \mathrm{mg} / \mathrm{ml}$ & p.o. & \multirow[t]{3}{*}{ Unified } \\
\hline & $\begin{array}{l}\text { Systemic } \\
\text { analgesics }\end{array}$ & ibuprofen & $\begin{array}{l}\text { Nurofen }{ }^{\circledR} \text { suspension, } 20 \mathrm{mg} / \mathrm{ml} \text { Reckitt } \\
\text { Benckiser, Budapest, Hungary }\end{array}$ & p.o. & \\
\hline \multirow{6}{*}{$\begin{array}{l}\text { Intra- } \\
\text { operative }\end{array}$} & $\begin{array}{l}\text { General } \\
\text { eanesthetic }\end{array}$ & sevoflurane & $\begin{array}{l}\text { Sevorane®, AbbVie S.r.l., Campoverde di } \\
\text { Aprilia (LT), Italy }\end{array}$ & inhalation & \\
\hline & Opioids & fentanyl & $\begin{array}{l}\text { Fentanyl-Richter }{ }^{\circledR} 50 \mu \mathrm{g} / \mathrm{ml} \text {, Richter Gedeon, } \\
\text { Budapest, Hungary }\end{array}$ & i.v. & \multirow[t]{10}{*}{ Optional } \\
\hline & & $\begin{array}{l}\text { nalbuphine } \\
\text { hydrochloride }\end{array}$ & $\begin{array}{l}\text { Nalbuphine Serb } \AA, 20 \mathrm{mg} / 2 \mathrm{ml} \text {, Serb } \\
\text { Laboratoires, Paris, France }\end{array}$ & i.v. & \\
\hline & $\mathrm{LA}$ & $\begin{array}{l}\text { lidocaine- } \\
\text { adrenaline }\end{array}$ & $\begin{array}{l}\text { Lidocaine-adrenalin } \AA 20 \mathrm{mg} / 0,01 \mathrm{mg} / \mathrm{ml} \text {, } \\
\text { EGIS, Budapest, Hungary }\end{array}$ & sm.inflitr. & \\
\hline & Antibiotics & $\begin{array}{l}\text { amoxicillin- } \\
\text { clavulanic acid }\end{array}$ & $\begin{array}{l}\text { Augmentin }{ }^{8} 500 \mathrm{mg} / 100 \mathrm{mg} \text {, Biopharma } \\
\text { S.r.l., Rome, Italy }\end{array}$ & i.v. & \\
\hline & $\begin{array}{l}\text { Anti- } \\
\text { hemorrhagic }\end{array}$ & etamsylat & Dicynone® 125 mg/ml solution & i.v. & \\
\hline \multirow{5}{*}{$\begin{array}{l}\text { Post- } \\
\text { operative }\end{array}$} & Opioids & $\begin{array}{l}\text { nalbuphine } \\
\text { hydrochloride }\end{array}$ & $\begin{array}{l}\text { Nalbuphine Serb®, } 20 \mathrm{mg} / 2 \mathrm{ml} \text {, Serb } \\
\text { Laboratoires, Paris, France }\end{array}$ & i.v. & \\
\hline & NSAIDs & ibuprofen & $\begin{array}{l}\text { Nurofen }{ }^{\circledR} \text { suspension, } 20 \mathrm{mg} / \mathrm{ml} \text { Reckitt } \\
\text { Benckiser, Budapest Hungary }\end{array}$ & p.o. & \\
\hline & & diclofenac & $\begin{array}{l}\text { Cataflam }{ }^{\circledR} \text {-suspension, } 15 \mathrm{mg} / \mathrm{ml} \text { Novartis } \\
\text { Hungaria, Budapest, Hungary }\end{array}$ & p.o. & \\
\hline & Antibiotics & $\begin{array}{l}\text { amoxicillin- } \\
\text { clavulanic acid }\end{array}$ & multiple manufacturer & p.o. & \\
\hline & Antiemetics & ondansetron & $\begin{array}{l}\text { Emetron } \circledast 2 \text { mg/ml, Richter Gedeon, } \\
\text { Budapest Hungary }\end{array}$ & i.v. & \\
\hline
\end{tabular}

\section{Statistical analysis}

The analysis was performed using SPSS (IBM Corporation, New York, USA, v25.0. A result was considered as statistically significant if $p<0.05$. Oral pain reported by children (WBS questionnaire) and the guardians (yes/no questionnaire) were analysed for all cases and for extraction cases only. Due to the non-normal distribution of the data all analyses were carried out with non-parametric tests: MannWhitney U-test was used to compare differences between two groups, while Kruskal-Wallis tests with Mann-Whitney post hoc analysis and Bonferroni type 1 error correction were applied in cases of several groups. Spearman's rho correlation analysis, Chi square tests or Fisher tests were used to examine correlations between two variables.

\section{Results}

One hundred three patients were enrolled in the study. Patient and intervention related data shown in table (Table 2.) 
Table 2

Data related to patients and interventions carried out during dental treatment under general anaesthesia.

\begin{tabular}{|lll|}
\hline $\begin{array}{l}\text { Patient related } \\
\text { parameters }\end{array}$ & male & 59 \\
\hline $\begin{array}{l}\text { Operation related } \\
\text { parameters }\end{array}$ & female & 44 \\
\hline average age (years) \pm SD & $5.07 \pm 2.55$ \\
\hline Length of treatment & $\begin{array}{l}96.41 \pm 43.63 \\
\text { minutes }\end{array}$ \\
\hline NTI & 8 cases \\
\hline Deciduous tooth filling & 95 cases \\
\hline Permanent tooth filling & 309 \\
\hline Deciduous tooth extraction & 20 \\
\hline Permanent tooth extraction & 459 \\
\hline Deciduous tooth pulpotomy & 15 \\
\hline Permanent tooth root canal treatment & 35 \\
\hline Only restorative treatment & 2 \\
\hline Administered intraoperative LA & 13 \\
\hline $\begin{array}{l}\text { Intraoperative systemic analgesia } \\
\text { Postoperative systemic analgesia during } \\
\text { hospitalization }\end{array}$ & 52 \\
\hline & 93 \\
\hline
\end{tabular}

\section{Questionnaires}

One hundred three parental questionnaires were returned and evaluated. Data of pain, reported by the guardians during the postoperative hospitalization period ( 3 occasions: on emergence, 3 and 6 hours later) were summarized. In three cases the WBS questionnaires were not returned or not fully completed. Therefore 100 questionnaires were suitable for evaluation.

\section{Results of Wong Baker FACES® Pain Rating Scale patient questionnaires}

The prevalence of pain reported by the children (regardless of severity) was $36.37 \%$ preoperatively, $66.66 \%$ in the postoperative observation period (6 hours after surgery) and $55.55 \%$ in the postoperative week (Figure 1.).

Extraction cases vs. non-extraction cases interestingly did not differ significantly in terms of presence or severity of pain during hospitalization (presence of pain: 59/86 extraction cases vs. 6/13 non-extraction cases, $p=0.128$; severity of pain: $2.51 \pm 2.31$, median $(\mathrm{me}): 0$, minimum $(\mathrm{min}): 0$, maximum(max): 10 
extraction cases, $1.74 \pm 2.41$, me: 0 , min: 0 , max: 10 non-extraction cases, $p=0.205$ ) or during the postoperative week (presence of pain: $p=0.362$; severity of pain: $0.55 \pm 0.83$, me: 0 , min: 0 , max: 10 extraction cases vs $1.43 \pm 1.87$, me: 0 , min: 0 , max: 10 non -extraction cases, $p=0.250$ ).

The patients' questionnaires showed no correlation between age and the presence of pain during hospitalization among all patients $(p=0.553)$ or extraction cases only $(p=0.214)$ (see details in supplementary Table 1.). No statistical difference related to the severity of pain was found (all: rho $=-0.066 ; p=0.511$; extraction: $r h o=-0.152 p=0.161$ ). Age positively correlated with the duration of pain in days (rho=0.204, $p=0.042$ ), and with the average severity of pain during the postoperative week (rho $=0.211, p=0.035)$ among all cases. However, it remained insignificant among extraction cases (duration: rho $=0.139 \mathrm{p}=0.202$; severity: rho $=0.163 \mathrm{p}=0.133$ ).

The gender of patients had no influence on the reported pain in any aspects. No significant difference was observed in the presence (all: $p=0.871$; extraction: $p=0.772$ ) and severity (all: $p=0.733$; extraction: $p=0.936$ ) of pain during hospitalization. The correlation between gender and the duration of pain during the postoperative week was also insignificant (all $p=0.793$; extraction: $p=0.622$ ) The average severity of pain during the postoperative week of all cases/extraction cases showed similarly insignificant results $(p=0.348$ and $p=0.622$ respectively) (Supplementary Table 2 .).

The length of the operation did not affect the presence of pain (all: $p=0.164$, extraction: $p=0.096$ ) or severity of the pain (all: rho $=0.105 ; p=0.300$ and extraction: rho $=0.129 ; p=0.235$ ) during the hospitalization. Significant positive correlation was found between the duration (all: rho $=0.287, p=0.004$; extraction: rho $=0.254 \mathrm{p}=0.001$ ) and severity of pain during the postoperative week (all: rho $=0.359$, $p=0.011$; extraction: $r h o=0.335, p=0.002$ ) (Supplementary Table 3.).

The use of NTI or LMA did not influence postoperative pain during hospitalization (presence- all: $p=0.224$; extraction: $p=0.199$; severity- all: $p=0.187$ extraction: $p=0.142$ ). NTI was associated with significantly longer (all: $p=0.024$;extraction: $p=0.026$ ) and more severe (all: $p=0.020$;extraction: $p=0.021$ ) pain during the postoperative week (Supplementary Table 4.).

Intraoperative systemic analgesia (nalbuphine/fentanyl or both) did not show correlation with the frequency (all: $p=0.575$; extraction: $p=0.403$ ) and severity (all: $p=0.614$; extraction: $p=0.473$ ) of reported pain during hospitalization (Supplementary Table 5).

LA did not influence pain (frequency: $p=0.673$; severity: $p=0.144$ ) during the hospitalization period. Surprisingly, $16 \%$ of children complained about numbness among those who did not even receive LA (Figure 2.) (Supplementary Table 6.).

Number of primary tooth extractions did not affect the presence or severity of pain during hospitalization (presence: $p=0.782$; severity: rho $=0.013 p=0.909$ ) or during the postoperative week (duration: rho $=0.179$ $p=0.099$ severity: $r h o=0.170 p=0.118$ ) (Supplementary Table 7.). 
The class of deciduous tooth extractions (anterior vs molar vs both) did not correlate with the presence or severity of pain during hospitalization (presence: $p=0.936$; severity: $p=0.798$ ). It did not affect the duration of pain either $(p=0.061)$, but in cases where only anterior tooth extractions were carried out, the average severity of pain during the postoperative week was significantly lower $(p=0.034)$ (Supplementary Table 7.).

Drugs used in postoperative pain management during hospitalization did not affect the frequency of postoperative pain for all cases (NSAID: $p=0.948$; opioid: $p=0.176$ ) or for extraction cases only (NSAID: $p=0.748$; opioid: $p=0.176$ ). Severity of pain during hospitalization was significantly lower in cases where opioids were administered intravenously (all: $p=0.024$; extraction: $p=0.038$ ). NSAIDs did not affect the severity of pain (all: $p=0.741$ extraction: $p=0.778$ ) (Supplementary Table 8 ).

In the extraction group intra- and postoperative antibiotic administration (amoxicillin/clavulanic acid) did not affect severity $(p=0.200)$ or duration of pain $(p=0.150)$ in the postoperative week (Supplementary Table 9.).

The severity of pain during hospitalization showed positive correlation with the duration of pain in the postoperative week (all: rho $=0.451, p<0.001$; extraction: $r h o=0.395, p<0.001$ ). It also influenced severity during the postoperative week (all: rho $=0.444, p<0.001$; extraction: rho $=0.385, p<0.001$ ). The average severity of pain was the highest after the intervention, and it gradually decreased during the postoperative week (Table 3). The average pain score declined below the average initial pain sensation on the second day after surgery.

Severity of pain during the hospitalization was significantly higher $(p=0.014)$ than baseline (before surgery) pain. On the first 4 consecutive days the patients did not experience significant difference in the pain level compared to the baseline pain ( $p=1.000$ for days $1-3$, and $p=0.223$ for day 4 ). Significantly lower average pain was reported from the fifth day $\left(p=0.013 ; 6^{\text {th }}\right.$ day: $p=0.007$ and $7^{\text {th }}$ day: $\left.p=0.003\right)$. The severity of pain on day one was not significantly different from pain registered during the hospitalization $(p=0.367)$. From the $2^{\text {nd }}$ day on it significantly declined $\left(2^{\text {nd }}\right.$ day: $p=0.001 ; 3^{\text {rd }}-7^{\text {th }}$ day: $\left.p<0.001\right)($ Table 3.$)$.

\section{Results of parental questionnaires}

In $33 \%$ oral pain was reported during hospitalization, but there was no significant difference between extraction and non-extraction cases $(p=0.214)$. Oral pain positively correlated with age (all: $p=0.001$; extraction: $p=0.012$ ) and duration of treatment (all: $p=0.007$; extraction: $p=0.015)$. Gender had no influence on pain (all: $p=0.532$; extraction: $p=0.214)$. The number $(p=0.453)$ and class of deciduous tooth $(p=0.490)$ extractions had no impact either. During the hospitalization postoperative analgesia had no influence on the frequency of pain (all: NSAID- $p=0.677$, opioid- $p=0.661$; extraction: NSAID- $p=0.391$, opioid- $p=0.654)$. The administration of LA did not affect the frequency of pain $(p=0.247)$ (Supplementary Table 1-3.) During the postoperative week $31.06 \%$ of the parents recorded oral pain (regardless of duration). Significantly more prolonged pain was reported in girls (all: $p=0.013$; extraction: $p=0.004$ ). Duration of pain did not correlate with age (all: rho $=0.190, p=0.055$; extraction: rho $=0.160 p=0.134$ ), 
length of treatment (all: rho $=0.059, p=0.555$; extraction: $r h o=0.067 p=0.531$ ), number of extractions (all: rho $=0.072 p=0.471$; extraction: rho $=0.170 p=0.112)$ or class of primary tooth extracted $(p=0.403)$.

Administration of antibiotics did not influence pain during the postoperative week $(p=0.136)$.

(Supplementary Table 1-9.)

Sore throat reported during hospitalization $(30 \%)$ positively correlated with age (all: $p<0.001)$ and length of treatment (all: $p=0.014$ ). Sore throat revealed no correlation with gender (all: $p=0.231$ ), type of airway device (extraction: $p=0.099$ ). Postoperative systemic analgesia did not affect the incidence of sore throat during the hospitalization (all: $\mathrm{p}=0.057$ ). (Supplementary Table 1-5, and 8 ).

Nasal pain reported during hospitalization (10\%) showed positive correlation with age (all: $p=0.017)$, but not with gender (all: $p=1.000)$, length of operation (all: $p=0.494$ ) or airway device (all: $p=1.000$ ) (Supplementary Table 1-4).

Presence of pain reported by both parents and children during hospitalization significantly correlated when analysed among all cases $(p=0.003)$ and extraction cases as well $(p=0.022)$ but did not show $100 \%$ overlap (Figure 3.)

Table 3

The severity of pain reported by the children before the dental treatment under general anaesthesia (morning of the intervention), during the hospitalization period, and the postoperative week daily. (*standard deviation)

\begin{tabular}{|llllll|}
\hline & Mean & SD* & Median & Minimum & Maximum \\
\hline Morning of operation (baseline) & 1.75 & 2.71 & 0.0 & 0 & 10 \\
\hline Hospitalization (day 0) & 2.43 & 2.32 & 2.5 & 0 & 10 \\
\hline 1st day & 1.70 & 2.30 & 0.0 & 0 & 8 \\
\hline 2nd day & 1.04 & 1.69 & 0.0 & 0 & 6 \\
\hline 3rd day & 0.75 & 1.66 & 0.0 & 0 & 10 \\
\hline 4th day & 0.59 & 1.50 & 0.0 & 0 & 10 \\
\hline 5th day & 0.36 & 1.14 & 0.0 & 0 & 6 \\
\hline 6th day & 0.26 & 0.87 & 0.0 & 0 & 4 \\
\hline 7th day & 0.24 & 1.18 & 0.0 & 0 & 10 \\
\hline
\end{tabular}

\section{Discussion}

Postoperative pain related to DTGA is common and may be overwhelming for the patients, their families, and the dental team [20]. Numerous factors influence pain experience. In our study we investigated unalterable (age, gender) and alterable (length of treatment, airway device, intra- and postoperative pain 
management, etc.) factors. Several correlations were observed with the severity and duration of postoperative pain. Postoperative pain was significantly more common and more intense than baseline pain (Fig. 2., Table 3.). This finding is in accordance with the results of Wong et al [21]. Our investigation revealed higher incidence of postoperative pain $(66.66 \%)$ than the pilot study of Fung et al. $(57.5 \%)$, but lower than reported by Atan and co-workers (74\%) or Hu et al. (82\%) [14, 22, 23]. Interestingly, older age showed positive correlation with both duration and severity of pain, as reported by parents/guardians and patients. This may be related to the increased number of interventions/extractions or may just be an individual variable among patients. Earlier $\mathrm{Hu}$ et al. showed that dental pain was significantly associated with the number of teeth treated but no correlation with age and postoperative dental morbidity could be proved [23]. This contradiction may be due to the wider age range and higher number of participants in our study. Needleman et al. suggested that older children require more analgesics postoperatively [24], supporting our results of pain-age correlation. According to guardians' questionnaires the duration of pain is longer in girls after DTGA. This was not evincible by the self-reported WBS questionnaires. Parents may have different perception regarding the pain of their children based on their gender. In contrast to our findings, Fung et al. showed younger age as a predicting factor for postoperative pain (self-reported) and it occurred more frequently in male patients. Their pilot study also revealed that one of the main influencing factors in postoperative pain is the relationship between the patient and the accompanying person. Children comforted by their mothers at the hospital complained more about postoperative pain [15]. In our present study we did not address this matter.

The length of treatment and the airway device used were alterable influencing factors in severity and duration of pain in the postoperative week. Patients experienced less severe and durable pain in the postoperative week, if treatment time was shorter and/or when LMA was applied (shorter operative time, few extractions). Lengthened operative time may result in prolonged and increased pain related either to the higher number of interventions, or pain derived from the surrounding tissues/organs (retraction of bucca, sustained and strained mouth opening). Atan et al. also concluded that the reduction of treatment time has the potential of reducing postoperative pain [14]. These findings could urge dental professionals to decrease the duration of treatment in general anaesthesia and maintain GA through laryngeal mask instead of nasotracheal intubation whenever it is possible. Unfortunately, numerous interventions or comprehensive dental care do not facilitate the use of LMA due to incapability of isolation against aspiration and the limited access to the oral cavity [25].

The treatment time should be shortened by careful treatment planning, especially when deciding upon the fate of a primary tooth. For precise planning, where possible, a radiographic survey is recommended prior to GA. The treatment approach may fall under exodontia, where extractions are carried out solely, or comprehensive care where a wide range of treatments are offered. Many factors may influence this choice (parental wishes, restorability, medical conditions, the clinically related factors, which include restorability, oral hygiene, or the care facilities). Exodontia is the least expensive treatment option, as less time and equipment are required for the intervention. Moreover, a radical treatment plan may decrease treatment time and can decrease the chance of need for repeated DTGA $[26,27]$. Nevertheless, the trend 
worldwide is to provide comprehensive treatment as long-term consequences of premature primary tooth loss should also be considered $[27,28,29]$.

It is recommended to carry out a comprehensive DTGA in a single appointment. Postponing restorations for future outpatient treatment lead to a high rate of repeated DTGA. Restoring teeth with questionable outcome should be avoided as opposed to single DTGA. Although permanent tooth endodontic therapy in DTGA revealed high success rate according to Cousson et al. [31], in primary dentition tooth extraction is recommended, where treatment success is doubtful [32].

Several studies have shown that postoperative pain following DTGA is associated with extractions [21, $22,30]$. The class of teeth extracted has not been evaluated in relation to the duration of pain. In our study patients having primary molar rather than anterior extractions solely reported more durable pain during the postoperative week. This is quite understandable as molar extractions leave a larger wound surface and are characterized by prolonged healing time. As deciduous incisors are the first teeth to exfoliate by the time of their extraction, they frequently present partially or completely resorbed roots.

Various studies support the use of LA as supplementary medication to reduce postoperative pain [16, 24, 32, 33]. Nevertheless, the use is still controversial. Sammons et al. reported less pain, where intraligamental anaesthesia was applied, but this difference was only apparent in the first postoperative hour [34]. In our study we found that the administration of LA before extractions did not affect postoperative pain, however, local numbness might be unpleasant. Those who oppose the use of LA report self-inflicted soft tissue trauma (morsication of the lips, cheeks, or tongue) due to loss of sensation $[16,35]$. We did not observe any of these injuries during follow-up appointments. The beneficial effect of LA, or soft tissue injuries may be absent due to the effect of the LA wearing off by the time the patients fully regain consciousness. In addition, extractions at the site of numbness reduce the chance of morsication. Surprisingly, $16 \%$ of the patients not receiving LA complained about numbness (Fig. 2). As numbness may be difficult to describe for those children who have never received LA before, some of our patients might not have been able to give reliable feedback on it.

The use of epinephrine containing LA can interfere with the control of bleeding, as delayed secondary bleeding may occur due to the relaxation of the blood vessels [36]. Drug interactions with opioids and possible complications of epinephrine containing anesthetics must also be taken into consideration when deciding upon the use of LA $[17,19]$.

Based on our experience supported by several studies, compared to acetaminophen the use of ibuprofen was superior in pre-emptive and postoperative pain management in dentistry. Where postoperative pain is associated with inflammation NSAIDs are considered as first-line agents by the American Academy of Pediatric Dentistry [37, 38, 39], while other studies advocate the use of acetaminophen [40]. In our study the severity of pain reported by patients receiving intravenous opioid analgesics (nalbuphine) during hospitalization was significantly lower compared to those who received NSAIDs only. Intraoperative and postoperative medications may influence our choice of postoperative pain management. Overlapping prescription of benzodiazepines and opioids increase the chance of respiratory depression [41, 42]. 
Non-oral pain, sore throat and nasal pain reported by the parents are most likely due to the NTI anaesthesia with pharyngeal pack. As described earlier, the use of LMA could prevent these complaints, however, comprehensive treatment (restorative treatment, multiple extractions) usually requires NTI.

We highlighted several important correlations, but we must acknowledge the limitations of the research as well. A limited number of certain complaints (nasal pain, sore throat) restricted reliable analysis, therefore we had to merge subgroups (medications). This might pose limitations to the results drawn. Self-reporting questionnaires always imply a risk for subjectivity (reporting bias). Data were collected retrospectively only from patients who returned our questionnaires (attrition and recall bias). No previous randomization was applied. The necessary treatment was determined by the operator and the medications administered were based on the choice of the medical team/anaesthetist. We did not investigate pain outcomes in relation to surgeons performing the interventions.

\section{Conclusion}

Dental treatment under general anaesthesia is thought to be an ideal option for non-cooperative, young and anxious children or where extensive treatment (oral surgery, multiple extractions) is indicated. Although this treatment modality is considered to be relatively safe, we must emphasize, that it is not without its own complications. These are mostly related to general anaesthesia and are well-discussed in the relevant literature [7]. The awareness of factors influencing postoperative pain in respect of the dental treatment is also indispensable for treatment planning.

Our results indicate that postoperative pain after DTGA is significantly higher compared to the preoperative pain level, which is an undesirable but inevitable consequence. As for any dental treatment, it is important to reduce pain and discomfort during and after dental interventions. Our study reveals factors which may be taken into consideration to achieve this goal. The use of LA in DTGA does not affect the pain postoperatively. Administration of opioid analgesics significantly reduces pain compared to NSAIDs. In the postoperative week more severe and prolonged pain can be expected in patients having undergone molar tooth extractions. During the week after DTGA pain experience correlates with the length of intervention, which indicates the need for well-established protocol (treatment plan) to be developed by the care providers to reduce operation time. Patients and parents should be informed about the potential, constantly subsiding postoperative pain, that may last for a week.

\section{List Of Abbreviations}

DTGA-dental treatment under general anaesthesia

GA- general anaesthesia

LA- local anaesthesia

NSAID- non-steroidal anti-inflammatory drug 
WBS- Wong-Baker FACES ${ }^{\circledR}$ Pain Rating Scale

LMA- laryngeal mask airway

NTI-nasotracheal intubation

p.o.: per os

i.v.: intravenous

sm. infiltr.- submucosal infiltration

\section{Declarations}

\section{Ethics approval and consent to participate:}

Our study was approved by the local ethics committee of the university (Regional Research Ethics Committee, Clinical Centre, University Pecs, Hungary, No.: 6823).

\section{Consent for publication}

N.A.

\section{Availability of data and materials}

All data generated or analysed during this study are included in this published article and its supplementary information files.

\section{Competing interests}

The authors declare that they have no competing interests

\section{Funding}

This research received founding from university sources: PTE-ÁOK KA.

\section{Authors' contributions}

Study was designed by KK and BS. Statistical analysis was planned and executed by NF. AR, KK, BS, ISZ, TK were involved in the interpretation of the data. The draft was written by AR and KK. The manuscript was revised by BS and AR. All authors read and approved the final manuscript.

\section{Acknowledgement}

Support was provided by departmental sources and Medical School, University of Pecs, Hungary. We would like to greatly acknowledge the help and expertise of Rébék-Nagy Gábor in the revision and 
correction of the manuscript.

\section{References}

1. American Academy of Pediatric dentistry. Behavior guidance for the pediatric dental patient. Pediatr Dent. 2017;39:246-259.

2. Macpherson LM, Pine CM, Tochel C, Burnside G, Hosey MT, Adair P. Factors influencing referral of children for dental extractions under general and local anaesthesia. Community Dent Health. 2005;22:282-288.

3. Klaassen MA, Veerkamp JS, Hoogstraten J. Young children's Oral Health-Related Quality of Life and dental fear after treatment under general anaesthesia: a randomized controlled trial. Eur J Oral Sci. 2009;117:273-278.

4. Park JS, Anthonappa RP, Yawary R, King NM, Martens LC. Oral health-related quality of life changes in children following dental treatment under general anaesthesia: a meta-analysis. Clin Oral Investig. 2018;22:2809-2818.

5. Hillebrecht AL, Hrasky V, Anten C, Wiegand A. Changes in the oral health-related quality of life in adult patients with intellectual disabilities after dental treatment under general anesthesia. Clin Oral Investig. 2019;23:3895-3903.

6. Jiang HF, Qin D, He SL, Wang JH. OHRQoL changes among Chinese preschool children following dental treatment under general anesthesia. Clin Oral Investig. 2019 Aug 21. doi: 10.1007/s00784019-03063-z. [Epub ahead of print]

7. Lim MAWT, Borromeo GL. The use of general anesthesia to facilitate dental treatment in adult patients with special needs. J Dent Anesth Pain Med. 2017;7:91-103. Review.

8. American Academy of Pediatric Dentistry. Guideline on use of anesthesia personnel in the administration of office-based deep sedation/general anesthesia to the pediatric dental patient. Pediatr Dent. 2016;38:246-249

9. Messieha Z. Risks of general anesthesia for the special needs dental patient. Spec Care Dentist. 2009;29:21-25.

10. Lee HH, Milgrom P, Starks H, Burke W. Trends in death associated with pediatric dental sedation and general anesthesia. Paediatr Anaesth. 2013;23:741-746.

11. Merry AF, Cooper JB, Soyannwo O, Wilson IH, Eichhorn JH. International Standards for a Safe Practice of Anesthesia 2010. Can J Anaesth. 2010;57:1027-1034.

12. Gottschalk A, Van Aken $H$, Zenz M, Standl T. Is anesthesia dangerous? Dtsch Arztebl Int. 2011;108:469-474.

13. United Stated Food and Drug Administration. Drug Safety Communication. FDA approves label changes for use of general anesthetic and sedation drugs in young children. Safety announcement (2016) https://www.fda.gov/media/104705/download. Accessed 08 September 2019 
14. Atan S, Ashely P, Gilthorpe MS, Scheer B, Mason C, Roberts G. Morbidity following dental treatment of children under intubation general anesthesia in a day-stay unit. Int J Pediatr Dent. 2004;14:9-16.

15. Farsi N, Ba'akdah R, Boker A, Almushayt A. Postoperative complications of pediatric dental general anesthesia procedure provided in Jeddah hospitals, Saudi Arabia. BMC Oral Health. 2009;9:6.

16. Townsend JA, Hagan JL, Smiley M. Use of local anesthesia during dental rehabilitation with general anesthesia: a survey of dentist anesthesiologists. Anesth Prog. 2014:61:11-17.

17. Becker DE, Reed KL. Essentials of local anesthetic pharmacology. Anesth Prog. 2006;53:98-108.

18. Townsend JA, Ganzberg S, Thikkurissy S. The effect of local anesthetic on quality of recovery characteristics following dental rehabilitation under general anesthesia in children. Anesth Prog. 2009;56:115-122.

19. American Academy of Pediatric dentistry. Use of local anesthesia for pediatric dental patients. Pediatr Dent. 2017;39:266-272.

20. AIQhtani FA, Pani SC. Parental anxiety associated with children undergoing dental treatment. Eur J Paediatr Dent. 2019;20:285-289.

21. Wong M, Copp PE, Haas DA. Postoperative Pain in Children After Dentistry Under General Anesthesia. Anesth Prog. 2015;62:140-152.

22. Fung DE, Cooper DJ, Barnard KM, Smith PB. Pain reported by children after dental extractions under general anaesthesia: a pilot study. Int J Paediatr Dent. 1993;3:23-28.

23. Hu YH, Tsai A, Ou-Yang LW, Chuang LC, Chang PC. Postoperative dental morbidity in children following dental treatment under general anesthesia. BMC Oral Health 2018;18:84.

24. Needleman HL, Harpavat S, Wu S, Allred EN, Berde C. Postoperative pain and other sequelae of dental rehabilitations performed on children under general anesthesia. Pediatr Dent. 2008;30:111121.

25. Tsukamoto M, Hitosugi T, Yokoyama T. Flexible laryngeal mask airway device for dental treatment cases associated with difficult intubation. J Dent Anesth Pain Med. 2017;17:61-64.

26. Harrison M, Nutting L. Repeat general anaesthesia for paediatric dentistry. Br Dent J. 2000;189:37-39.

27. Savanheimo N, Vehkalahti MM. Five-year follow-up of children receiving comprehensive dental care under general anesthesia. BMC Oral Health 2014;14:154.

28. Knapp R, Marshman Z, Rodd H. Treatment of dental caries under general anaesthetic in children. BDJ Team. 2017;4:17116.

29. Law CS. Management of premature primary tooth loss in the child patient. J Calif Dent Assoc. 2013;41:612-618.

30. O'Donnell A, Henderson M, Fearne J, O'Donnell D. Management of postoperative pain in children following extractions of primary teeth under general anaesthesia: a comparison of paracetamol, Voltarol and no analgesia. Int J Paediatr Dent. 2007;17:110-115.

31. Cousson PY, Nicolas E, Hennequin M. A follow-up study of pulpotomies and root canal treatments performed under general anaesthesia. Clin Oral Investig. 2014;18:1155-1163. 
32. Ramazani N. Different aspects of General anesthesia in pediatric dentistry: A review. Iran J Pediatr. 2016;26:e2613. Review.

33. Kaufman E, Epstein JB, Gorsky M, Jackson DL, Kadari A. Preemptive analgesia and local anesthesia as a supplement to general anesthesia: A review. Anes Progress. 2005;52:29-38.

34. Sammons HM, Unsworth V, Gray C, Choonara I, Cherrill J, Quirke W. Randomized controlled trial of the intraligamental use of a local anaesthetic (lignocaine $2 \%$ ) versus controls in paediatric tooth extraction. Int J Paediatr Dent. 2007;17:297-303.

35. Townsend JA, Martin A, Hagan JL, Needleman H. The use of local anesthesia during dental rehabilitations: a survey of AAPD members. Pediatr Dent. 2013;35:422-425.

36. Czembirek C, Poeschl WP, Eder-Czembirek C, Fischer MB, Perisanidis C, Jesch P, et al. Causes and timing of delayed bleeding after oral surgery. Clin Oral Investig. 2014;18:1655-1661.

37. Baygin O, Tuzuner T, Isik B, Kusgoz A, Tanriver M. Comparison of pre-emptive ibuprofen, paracetamol, and placebo administration in reducing post-operative pain in primary tooth extraction. Int J Paediatr Dent. 2011;21:306-213.

38. Bailey $E$, Worthington $H$, Coulthard $P$. Ibuprofen and/or paracetamol (acetaminophen) for pain relief after surgical removal of lower wisdom teeth, a Cochrane systematic review. $\mathrm{Br}$ Dent $\mathrm{J}$. 2014;216:451-455. Review.

39. American Academy of Pediatric Dentristy. Policy on acute pediatric dental pain management. Pediatr Dent. 2017;39:99-101.

40. Hutchinson S. General anaesthesia for dentistry. Anaesthesia and Intensive Care Medicine 2014;15:366-369.

41. Dowell D, Haegerich TM, Chou R. CDC guideline for prescribing opioids for chronic pain - United States, 2016. JAMA. 2016;315:1624-1645.

42. American Academy of Pediatric Dentistry. Pain Management in Infants, Children, Adolescents and Individuals with Special Health Care Needs. Oral Health Policies \& Recommendations (The Reference Manual of Pediatric Dentistry). 2019-2020/P.331-339. (https://www.aapd.org/research/oral-healthpolicies-recommendations/pain-management-in-infants-children-adolescents-and-individuals-withspecial-health-care-needs/\#section-references. Accessed 29 January, 2020)

\section{Figures}




\section{Prevalence and incidence of pain reported by the children}

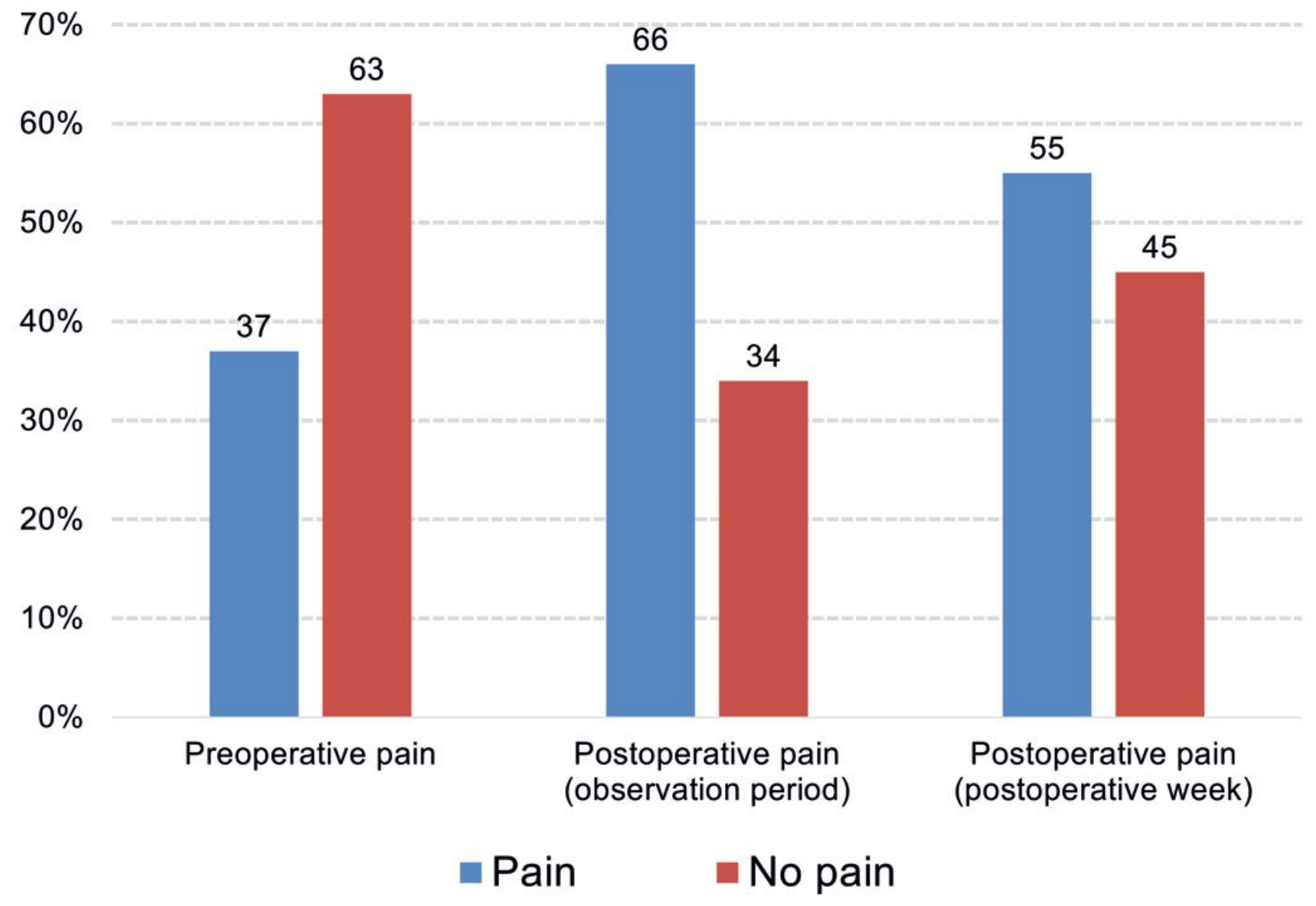

Figure 1

Prevalence and incidence of pain reported by the children in the preoperative, postoperative observational period (within 6 hours after the intervention) and during the first postoperative week. 


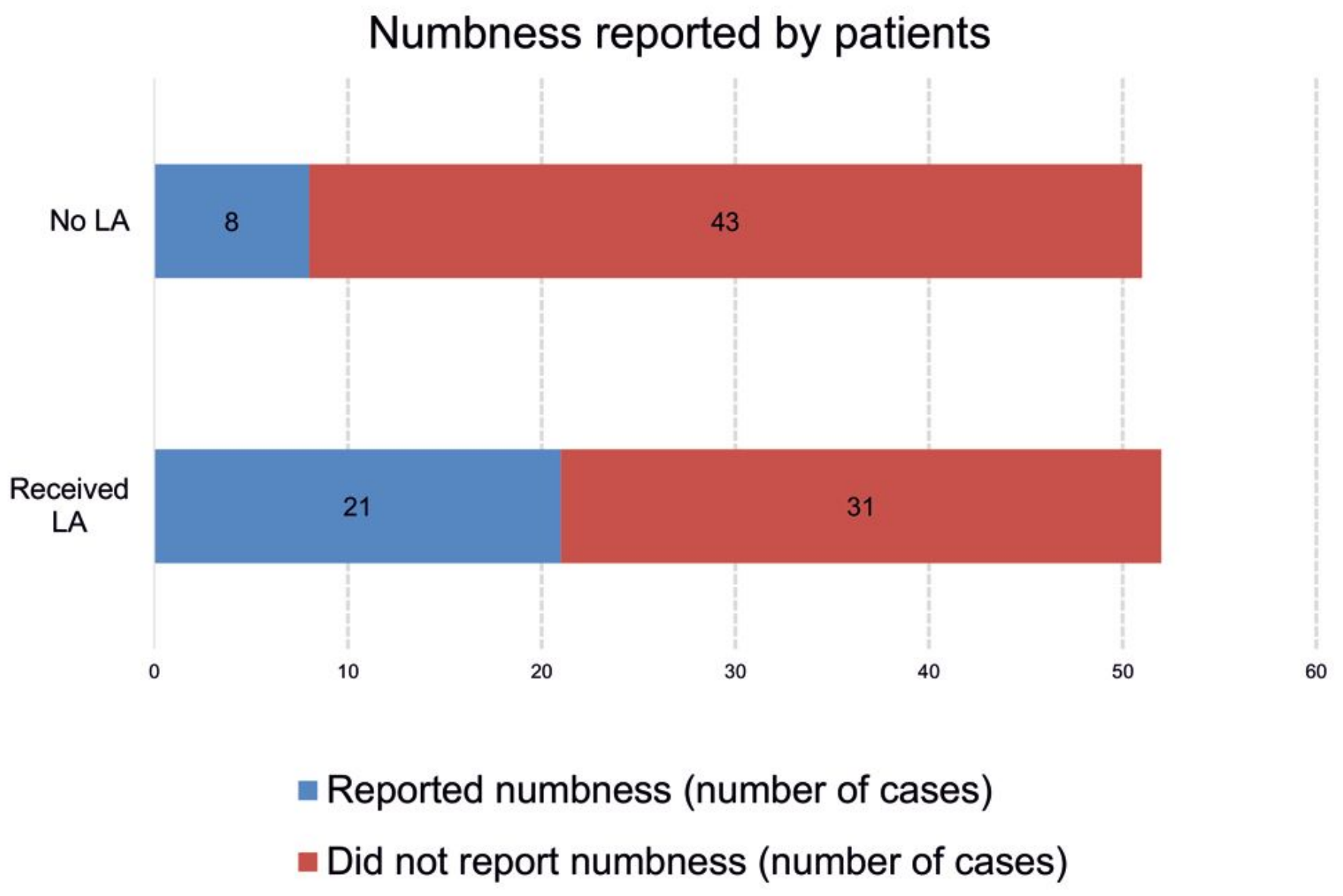

\section{Figure 2}

Numbness reported postoperatively by patients: note that $16 \%$ of the responders who did not receive local anesthesia complained about numbness. 


\section{Frequency of reported pain}

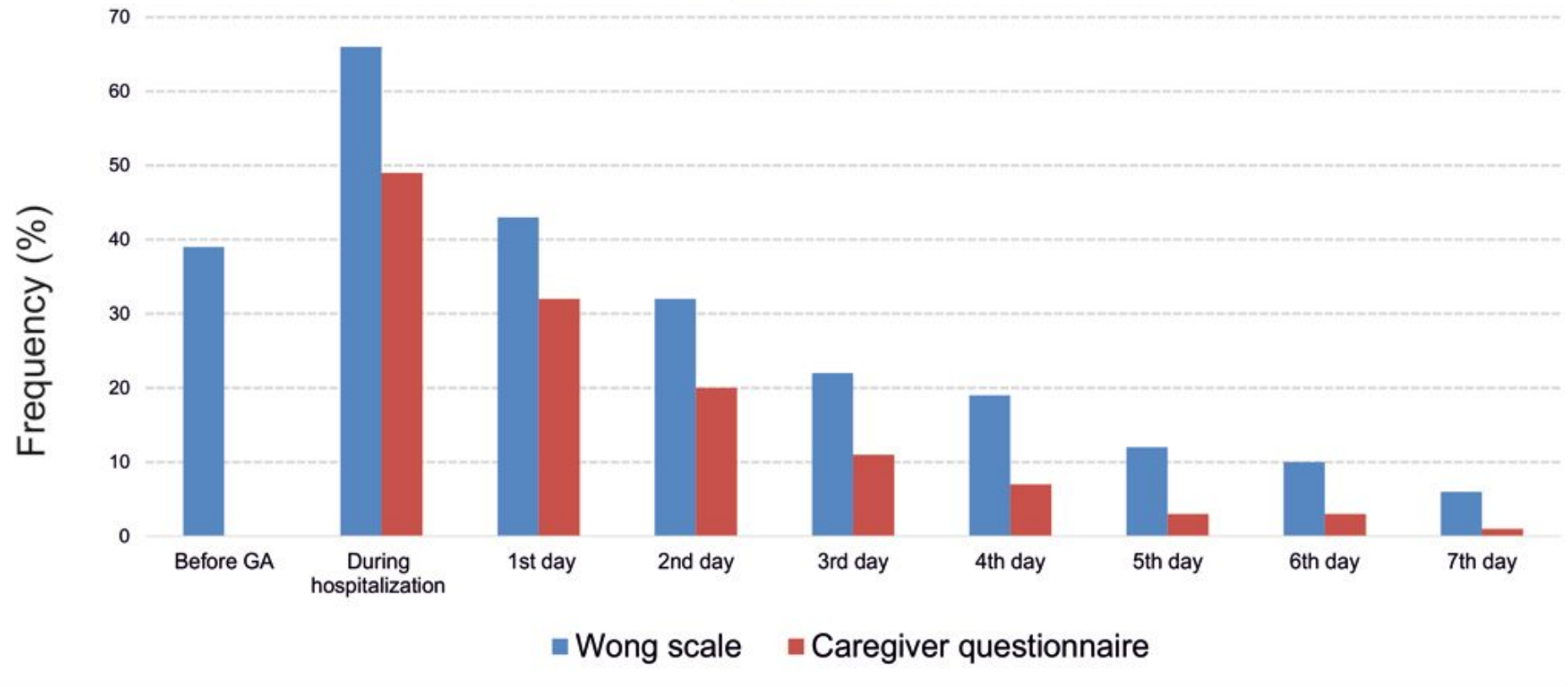

\section{Figure 3}

Frequency of pain reported by children and guardians: note the constantly decreasing frequency of pain reported both by children (Wong Baker FACES® Pain Rating Scale) and guardians. At any given time, guardians reported pain less frequently.

\section{Supplementary Files}

This is a list of supplementary files associated with this preprint. Click to download.

- S9Table.xIsx

- S8Table.xlsx

- S7Table.xIsx

- S6Table.xlsx

- S5Table.xIsx

- S4Table.xlsx

- S3Table.xlsx

- S2Table.xlsx

- S1Table.xlsx 